Bangl. J. Vet. Med. (2007). 5 (1 \& 2): 63-69

\title{
PREVALENCE, POPULATION DYNAMICS AND PATHOLOGICAL EFFECTS OF INTESTINAL HELMINTHS IN BLACK BENGAL GOATS
}

\author{
U. K. Mohanta ${ }^{* 1}$, Anisuzzaman, T. Farjana, P. M. Das², S. Majumder ${ }^{3}$ and M. M. H. Mondal \\ Department of Parasitology, ${ }^{2}$ Department of Pathology, Faculty of Veterinary Science, Bangladesh Agricultural \\ University, Mymensingh-2202, Bangladesh
}

\begin{abstract}
Prevalence, population dynamics and pathological effects of intestinal helminths in Black Bengal goats were studied by examining 150 viscera collecting from different slaughter houses of Mymensingh district from the period of November 2005 to May 2006 in the Department of Parasitology and Pathology, Bangladesh Agricultural University, Mymensingh, of which $94.67 \%$ goats were infected with one or more species of helminths. A total of 5 species of helminth parasites were identified such as Oesophagostomum columbianum (92\%), Trchuris ovis (56.66\%), Schistosoma indicum (38\%), Moniezia expansa (10.66\%) and Moniezia benedeni (2.66\%). Single infection was observed in case of O. columbianum (16\%) and S. indicum (2.66\%). Single sex infection was established by $S$. indicum male (5.33\%). Overall mean parasitic burden was 34.02 \pm 2.20 . Mean parasitic burden was the highest in case of O. columbianum (29.91 \pm 2.00$)$ followed by that of $T$. ovis (5.70 \pm 0.47$), S$. indicum (4.66 \pm 0.42$), M$. expansa (2.59 \pm 0.54$)$ and $M$. benedeni (1.00 \pm 00$)$. Prevalence of intestinal helminth was significantly $(\mathrm{P}<0.05)$ higher in winter $(100 \%)$ than that in summer $(89.33 \%)$. Calculated odds ratio in between winter and summer was 18 , which indicated that Black Bengal goats were 18 times more susceptible to helminth infection in winter. Parasitic burden was also higher in winter (41.53 \pm 3.15$)$ than that in summer (25.52 \pm 2.57$)$ season. Pathological lesions were observed in case of $O$. columbianum, $T$. ovis and $S$. indicum infection. In $O$. columbianum infection, hard, raised, slightly yellowish to greenish colored nodules measuring $0.25 \times 0.50 \mathrm{~cm}$ were observed. Microscopically, it was characterized by catarrhal inflammation associated with destruction and desquamation of epithelial cells. Affected tissues were infiltrated chiefly with lymphocytes, macrophages, a few eosinophils and occasionally with plasma cells and neutrophils. Caseation and fibrous tissue proliferation were also noticed. But moderate infection with $T$. ovis was characterized by catarrhal inflammation along with the petechial haemorrhages on the intestinal mucosa where parasites were firmly attached. Histopathologically, it was characterized by destruction of lining epithelium of villi of caecum and colon along with the cellular infiltration predominantly with lymphocytes, few eosinophils and occasionally by macrophages. Lymph nodes of the lamina propria were enlarged. In case of $S$. indicum infection, haemorrhages were observed particularly on the rectal mucosa. Numerous eggs were found in the mucosal scraping from intestinal surface. Microscopically, lamina propria was thick and inflammed. Granulomatous response was observed which was characterized by the infiltration of epitheloid cells and proliferation of fibroblasts. The present study clearly suggests that Black Bengal goats are susceptible to intestinal helminths in both winter and summer seasons and most of the parasites recovered were associated with the production of variable degree of pathological lesions. That is why proper attempts should be made to control all these parasites.
\end{abstract}

Key words: Prevalence, population dynamics, pathological effects, intestinal helminths, goat

\section{INTRODUCTION}

In Bangladesh, there are about 34.5 millions of goats (FAO, 2003). About $97.90 \%$ of goats are distributed in rural areas and $2.10 \%$ in urban areas (BBS, 1986). In addition to its production of high quality of meat, Black Bengal goat provides world famous skin. But goat rearing is hindered by various problems, among them parasitism is an important limiting factor especially in Bangladesh as because the climatic condition of the country favors the development and survival of various parasites. In fact, goats of Bangladesh are affected by various intestinal helminths (Qadir, 1967; Haq and Shaikh, 1968). These parasites reduce appetite with concomitant reduction of food intake, an increased passage of food through the digestive tract, indirectly may be the cause of decreased food utilization and eventually decrease the synthesis of protein in the skeletal muscle (Soulsby, 1965).

Present address: ${ }^{* 1}$ Corresponding author, Animal Health Research Division, BLRI, Regional Station, Naikhongchari, Bandarban, ${ }^{3}$ Department of Agricultural Statistics, BAU, Mymensingh-2202, Bangladesh. 
So far, except some preliminary observation, very little attention has been paid to determine the population dynamics, seasonal prevalence and to study the pathological conditions produced by intestinal helminths in Black Bengal goats in Bangladesh. Therefore, the present research work was undertaken to study prevalence, population dynamics, effects of seasons on the prevalence of intestinal helminths in Black Bengal goats in Bangladesh and pathological effects produced by them.

\section{MATERIALS AND METHODS}

\section{Prevalence and population dynamics of intestinal helminths}

The investigation was carried out in the Department of Parasitology, Bangladesh Agricultural University, Mymensingh during the period from November 2005 to May 2006. Animals were selected from different slaughter houses of Mymensingh district and thoroughly investigated to detect the general health conditions and the clinical manifestations of parasitic diseases such as emaciation, diarrhoea, anaemia, bottle jaw. Immediately after slaughter, the intestines were collected after giving knots on both ends such as at the starting of the duodenum and ending of the rectum. Then the intestines were brought to the laboratory packing in a polythene bag as soon as possible. After shifting to the laboratory, the intestines were examined carefully from the parietal surface for the detection of gross pathological changes, if any. Then the intestine was cut along the log axis with the help of scissors and the internal mucus membranes were also thoroughly examined. Parasites were collected according to the procedures described by Urquhart et al. (1996). Collected parasites were washed several times in normal saline, and nematodes were preserved in luke-worm $70 \%$ alcohol but trematodes and cestodes were preserved in $10 \%$ formalin. Nematodes were identified by preparing temporary slides adding one drop of lactophenol (Cable, 1957) following the keys and descriptions given by Yamaguti (1961) and Soulsby (1982). Cestodes and trematodes were identified by preparing permanent slides (Cable, 1957) by using the keys and descriptions of Yamaguti (1958) and Soulsby (1982).

\section{Pathological lesions}

A portion of the affected tissues were collected and fixed in $10 \%$ buffered neutral formalin for histopathological studies. Histopathological studies were made by processing and staining of the well-fixed tissues following the procedures of Luna (1968).

\section{Statistical analysis}

Specific parasite wise prevalence in the Black Bengal goat in winter season was compared with that in summer season by Chi-square test (Mostafa, 1989). The risk of developing different intestinal helminth parasitic infection in a Black Bengal goat in winter season was compared with that in summer by computing Odds ratio (Schlesselman, 1982). Comparison of mean parasitic load of the infected animals between winter and summer seasons was performed by t-test (Petrie and Watson, 1999).

\section{RESULTS AND DISCUSSION}

\section{Prevalence and population dynamics}

From the study it was evident that prevalence of gastrointestinal helminths in Black Bengal goats was very high (94.67\%) (Table 1). Similar experiments were conducted by earlier scientists in different breeds of goats in various countries. Hassan (1964) reported that $82.1 \%$ goats were positive for helminth infections whereas Patel et al. (2001) recorded 54.92\% gastrointestinal helminth infection in goats in India. However, this variation in between the present and earlier results might be due to the differences among the geographical locations and climatic conditions of the experimental areas, method of study, sample size, breed of the animals. Bangladesh is a tropical country with moderate winter and summer. This climatic condition is suitable for the development and survival of many parasites. Besides, in this country most of the goats are reared in rural areas in scavenging or semi scavenging system (Devendra, 1970). In this type of rearing, goats graze on the fields. Probably, this type of management practice plays a vital role in the high rate of parasitic infection. 
Table 1. Prevalence and population dynamics of intestinal helminth parasites in Black Bengal goats

\begin{tabular}{|lll|ll|}
\hline Name of parasites & $\begin{array}{l}\text { Number of animals infected } \\
(\mathrm{n}=150)\end{array}$ & $\begin{array}{l}\text { Prevalence } \\
(\%)\end{array}$ & & Worm load \\
\cline { 4 - 5 } & & 92 & Range & Mean \pm SE \\
\hline O. columbianum & 138 & 56.66 & $2-114$ & $29.91 \pm 2.00$ \\
T. ovis & 85 & 38 & $1-17$ & $5.70 \pm 0.47$ \\
S. indicum & 56 & 10.66 & $1-13$ & $4.66 \pm 0.42$ \\
M. expansa & 17 & 2.66 & $1-9$ & $2.59 \pm 0.54$ \\
M. benedeni & 4 & 94.67 & $1-114$ & $34.02 \pm 2.20$ \\
\hline Total & 142 & & & \\
\hline
\end{tabular}

$\mathrm{n}=$ No. of animals examined.

Prevalence of $O$. columbianum (92\%) was the highest but that of $M$. benedeni (2.66\%) was the lowest (Table 1). Same type of experiment was carried out by Hassan (1964) who reported that $92.7 \%$ goats were positive to Oesophagostomum spp. and 10.9\% to Moniezia spp.infection. Qadir (1967) and Haq and Shaikh (1968) also recorded the high prevalence of $O$. columbianum in goats in Mymensingh district throughout the year. The cause of higher prevalence of $O$. columbianum can not be explained exactly but it can be assumed that bionomics of this parasite may be associated with this matter. O. columbianum maintain direct life cycle in which third stage larva $\left(\mathrm{L}_{3}\right)$ is infective stage. Goats become infected by the ingestion of these infective larvae with the contaminated foodstuff during grazing. But these larvae are capable of free movements and can climb up on the grass blades. They are positively hydrotropic and negatively phototropic. So, they are abundant on the grass blades especially during the morning and in the evening (Soulsby, 1982). On the other hand, goats are habituated in the eating of grass from the top level (Devendra, 1970). Therefore, chance of gaining infection with $O$. columbianum in Black Bengal goat remains very high. Besides, in this study, viscera were collected from the slaughterhouse. So, obviously almost all goats were adult. But infection with Moniezia spp. usually occurs in young goats (Soulsby, 1982). This sampling error might have an effect on the prevalence of Moniezia spp. during the present study. However, utmost attempts were made to minimize this sampling error during sample collection.

Prevalence of $T$. ovis was 56.66\% in Black Bengal Goats. In case of T. ovis, infective stage is egg containing first stage larva (Soulsby, 1982), and goats become infected by the ingestion of infective eggs during grazing. In this case, infective eggs are not capable of active movement. So, they remain at the level of grass root (soil). So, chance of infection in browser goats with $T$. ovis remains logically relatively lower than that of the $O$. columbianum.

In this study, infection with only single species of parasite was observed, which was caused by $O$. columbianum (16\%) and S. indicum (2.66\%). But this result cannot be compared and contrast due to the lack of relevant literature. Exact mechanism of single infection is not known. However, Black Bengal goats may be more susceptible to the infection with these parasites than other parasites recovered. Besides, the fecundity of these parasites may also be higher and developmental stages of them probably can withstand the environmental stresses. Available literature suggests that their larvae develops at temperature from $15-37^{0} \mathrm{C}$ but the optimum temperature is $30^{\circ} \mathrm{C}$. In room temperature infective larvae can survive for 103 days (Agrawal, 1966).

Single sex infection with the male of $S$. indicum was also observed. Single sex infection in Black Bengal goats with S. indicum was also reported by Qadir (1979) in Bangladesh. Probably in these goats, infection occurred by the cercariae derived from single egg. Infected goats harbored more O. columbianum (29.91 \pm 2.00$)$ than the other parasites recovered (Table 1). This result can not be compared due to paucity of relevant literature. The exact mechanism of higher parasitic burden of O. columbianum in Black Bengal goats is not known. In fact, high prevalence and parasitic load suggest the good host parasitic relationship.

Prevalence of $S$. indicum was higher in the summer (52\%) than the winter (22.66\%) season (Table 2). In winter season, many snails undergo hibernation (Kotpal, 2001). Many snails die under the mud in the winter. So there is scarcity of snail intermediate hosts of S. indicum in the environment. Besides, in hibernating snails, paediogenesis of trematode is significantly low (Urquhart et al., 1996). On the other hand, later part of summer, raining usually occurs in Bangladesh and snails become available. Probably these factors play an important role in the higher prevalence of $S$. indicum in Black Bengal goats in summer. 
Table 2. Prevalence and population dynamics of helminth parasites in Black Bengal goat in summer and winter seasons

\begin{tabular}{|c|c|c|c|c|c|c|c|c|}
\hline \multirow{4}{*}{$\begin{array}{l}\text { Name of } \\
\text { parasites }\end{array}$} & \multicolumn{6}{|c|}{ Season } & \multirow{4}{*}{$\begin{array}{l}\text { Chi-Square } \\
\text { value }\end{array}$} & \multirow[t]{4}{*}{ P-value } \\
\hline & \multicolumn{3}{|c|}{ Winter $(\mathrm{n}=75)$} & \multicolumn{3}{|c|}{ Summer $(\mathrm{n}=75)$} & & \\
\hline & \multicolumn{2}{|c|}{$\begin{array}{l}\text { Animals } \\
\text { infected }\end{array}$} & \multirow[t]{2}{*}{ Worm load } & \multicolumn{2}{|c|}{$\begin{array}{l}\text { Animals } \\
\text { infected }\end{array}$} & \multirow[t]{2}{*}{ Worm load } & & \\
\hline & No. & $\%$ & & No. & $\%$ & & & \\
\hline O. columbianum & 75 & 100 & $\begin{array}{l}3-114^{\mathrm{a}} \\
35.00 \pm 2.86^{\mathrm{b}}\end{array}$ & 63 & 84 & $\begin{array}{l}2-82^{\mathrm{a}} \\
23.86 \pm 2.59^{\mathrm{b}}\end{array}$ & 13.04 & $<0.001$ \\
\hline T. ovis & 54 & 72.05 & $\begin{array}{l}1-17 \\
6.98 \pm 0.64\end{array}$ & 32 & 42.66 & $\begin{array}{l}1-9 \\
3.53 \pm 0.45\end{array}$ & 13.19 & $<0.001$ \\
\hline S. indicum & 17 & 22.66 & $\begin{array}{l}1-9 \\
4.29 \pm 0.53\end{array}$ & 39 & 52 & $\begin{array}{l}1-13 \\
4.82 \pm 0.56\end{array}$ & 13.79 & $<0.001$ \\
\hline M. expansa & 13 & 17.33 & $\begin{array}{l}1-9 \\
2.77 \pm 0.69\end{array}$ & 4 & 5.33 & $\begin{array}{l}1-3 \\
2.00 \pm 0.41\end{array}$ & 0.37 & 0.02 \\
\hline M. benedeni & 4 & 5.33 & $\begin{array}{l}1 \\
1.00 \pm 0\end{array}$ & 0 & - & - & 4.11 & 0.043 \\
\hline Total & 75 & 100 & $\begin{array}{l}1-114 \\
41.53 \pm 3.15\end{array}$ & 67 & 89.33 & $\begin{array}{l}1-82 \\
25.52 \pm 2.57\end{array}$ & 0.41 & 0.021 \\
\hline
\end{tabular}

$\mathrm{n}=$ No. of animals examined, ${ }^{\mathrm{a}}$ Range, ${ }^{\mathrm{b}}$ Mean \pm SE.

Contemporarily, prevalence of other gastrointestinal helminths identified (except $S$. indicum), was relatively higher in winter than that in the summer (Table 2). Almost Similar studies were conducted by Asanji and Williams (1987), who reported increased helminth infection from August to January in Africa. They recorded the highest and lowest relative densities in October and July respectively. In Bangladesh, winter usually begins with mild cold and passes through moderate cold and temperature ranging from $18.03-23.66^{\circ} \mathrm{C}$. This climatic condition is suitable for the development and survival of many geo-parasites like Oesophagostomum spp., Trichuris spp. etc. Arthropod vectors like oribatid mites (which transmit Moniezia spp.), which live on the pasture, are more available in winter than summer (Urquhart et al., 1996). Probably for these reasons, prevalence of such type of helminth parasites was relatively higher in winter.

\section{Pathological lesions in helminth infection}

\section{O. columbianum}

Grossly nodule formation was commonly observed in $O$. columbianum infection. Nodules were hard, raised,

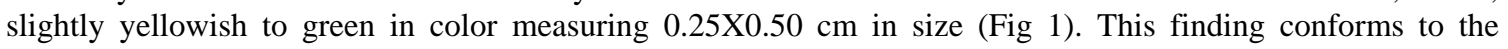
findings of Lapage (1962), Soulsby (1965) and Smith et al. (1992). The larvae penetrate the mucosa at any point from the pylorus to the anus in order to reach the deeper parts of the sub-mucosa where they encyst and undergo moulting. Local tissue sensitivity develops in animals due to repeated exposure to these parasites and the subsequent entry of the larvae into the submucosae which provokes an intense tissue reaction. The parasites produce some glandular secretions (Cephalic and oesophageal) which considered as responsible for the chronic inflammation in the intestinal wall (Smith et al., 1992; Lapage, 1962) resulting proliferation of the fibrous tissues. Histologically the lesions were characterized by the infiltration of large numbers of eosinophils, lymphocytes, macrophages and by the formation of foreign body giant cells. Besides, destruction and desquamation of epithelial cells of intestinal wall associated with the hyperplasia of the goblet cells and infiltration of plasma cells were noticed (Fig. 2 \& 3). Thangathurai and Rao (2002), Powers (1961), Soulsby (1965) and Mondal and Islam (1994) observed the similar changes. Cross or longitudinal sections of parasites were not observed possibly due to the section of tissues in improper angle. 


\section{Intestinal helminths in goats}

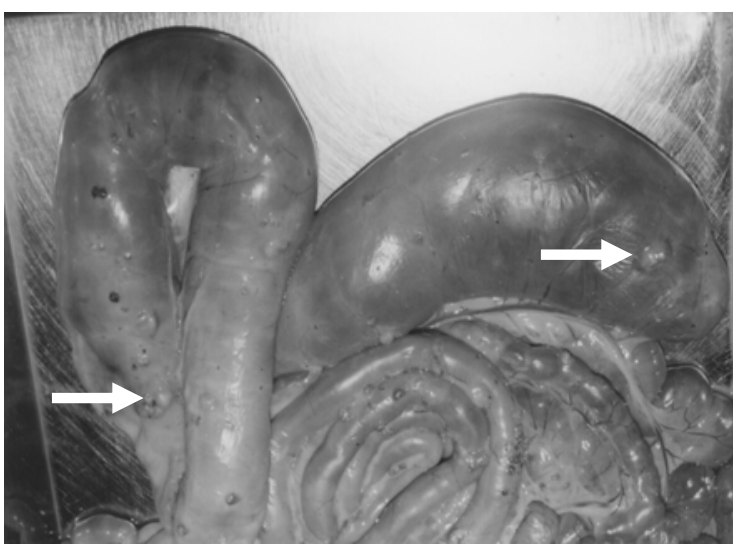

Fig. 1. Nodular lesions (arrows) on the intestinal wall due to $O$. columbianum infection.

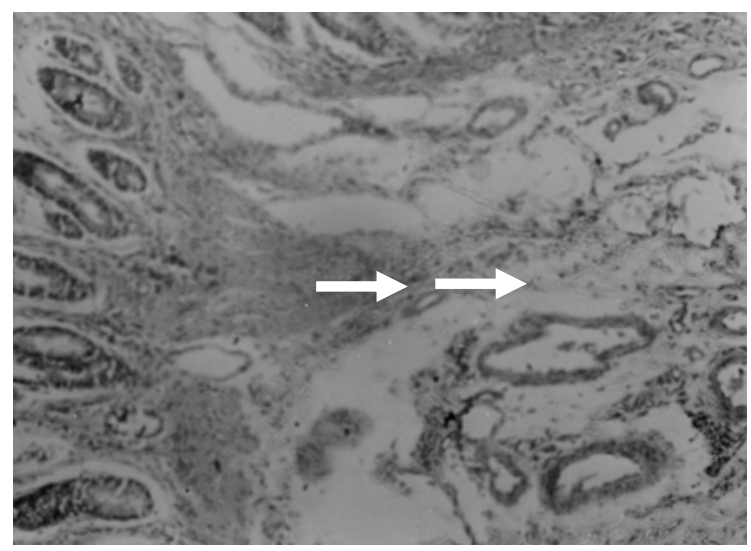

Fig. 3. Fibroblastic proliferation (arrows) due to O. columbianum infection (84x).

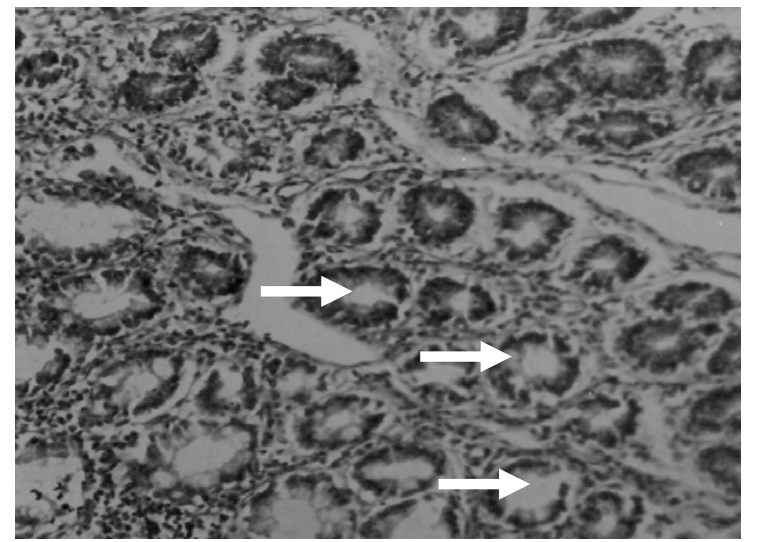

Fig. 2. Glandular hyperplasia and cystic glandular appearance (arrows) with mononucleur cellular infiltration in the lamina propria due to $O$. columbianum infection (84x).

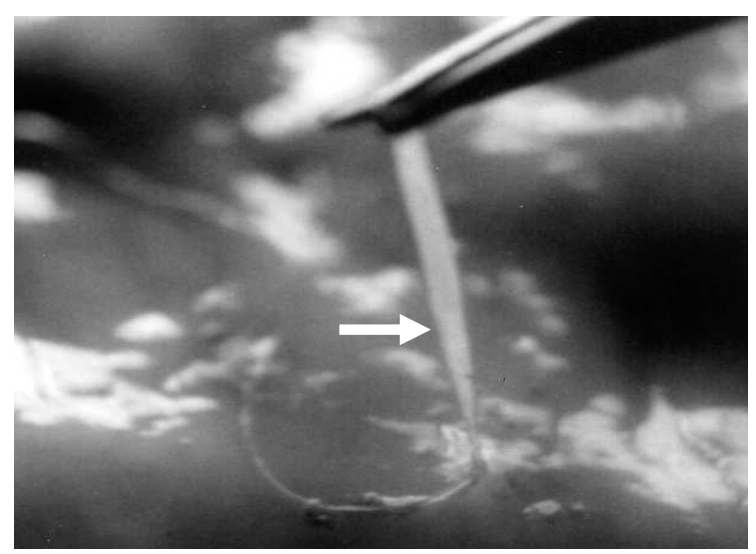

Fig. 4. Accumulation of mucus in caecum and colon with attached $T$. ovis (arrow).

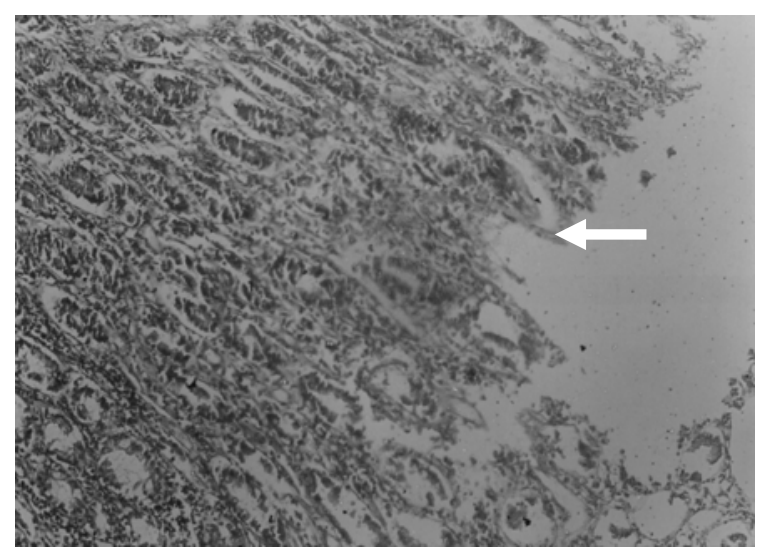

Fig. 5. Destruction of lining epithelium of villi (arrow) with cellular infiltration in T. ovis infection $(84 \mathrm{x})$. 


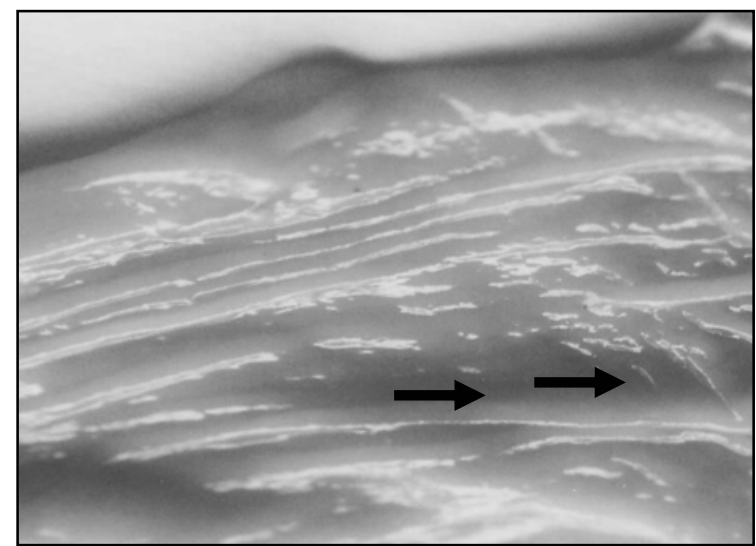

Fig. 6. Haemorrhagic striation (arrows) on the rectal mucosa due to $S$. indicum infection.

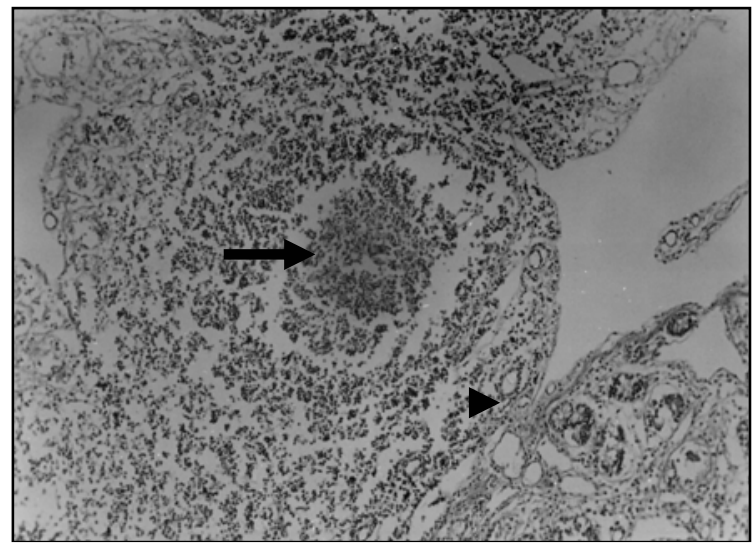

Fig. 7. Granulomatous lesions characterized by infiltration of epitheliod (arrow) and fibroblast cells and fibrous tissue proliferation in lamina propria (arrow head) due to $S$. indicum infection (84x).

\section{T. ovis}

In moderate infection, slight catarrhal inflammation along with the anchored parasites was observed (Fig. 4). Petechial haemorrhages on the mucosa, cellular infiltration such as infiltration of lymphocytes, eosinophils and macrophages on the caecum and colon and proliferation of goblet cells were noticed. Destruction and desquamation of lining epithelium of intestine were detected (Fig. 5). This finding is conformed to the observations of Kumar and Lal (1987) and Saha and Bhowmik (1998). T. ovis penetrates the intestinal wall by their anterior parts. Probably during the process of penetration, they cause mild to moderate degree of damage in the intestinal surface, resulting petecheal haemorrhages. As the parasitic infection is a long standing insult on the intestinal wall, especially in untreated cases, so they cause destruction of the lining epithelium where they predominantly inhabit. Due to this continuous irritation of the adult parasites on the intestinal wall, catarrhal inflammation occurs. That is why goblet cells were increased in numbers and size (Soulsby, 1965). In trichurosis, lymphoid nodules on the lamina propria were enlarged from which it can be assumed that the parasite may produce some chemical mediators that cause lymphoid proliferation locally.

\section{S. indicum}

Haemorrhagic lesions were observed mainly on the rectal mucosa (Fig. 6). Numerous eggs were found in the mucosal scraping. The lamina propria was thick and inflammed and in some cases there was marked granulomatous response around eggs, which was characterized by the infiltration with epitheloid cells and proliferation of fibroblasts (Fig. 7). These findings were almost similar to the observations of Singh and Parihar (1990). Adult parasites live in the mesenteric blood vessels where they lay eggs. The eggs have spine. From the mesenteric vein the eggs lodge in the intestinal capillary and break the capillary wall to enter into the intestinal lumen. During this migration the spiny eggs sets up an inflammatory reactions around the eggs (Soulsby, 1965). Probably thus they produce haemorrhages in the intestine. Possibly these inflammatory reactions call-forth inflammatory cells such as eosinophils, lymphocytes, macrophages and plasma cells which provokes granulomatous response. In most of the parasitic infections, eosinophilic infiltration is mainly seen. On the other hand, granulomatous inflammation is produced in long standing chronic cases. Perhaps at first exposure, adult parasites themselves and their eggs and other products and byproducts cause sensitization. In the subsequent infection, profound granulomatous response occurs in those sensitized animals. Fibrous proliferation usually occurs in response to fibrogenic cytokines produced by sensitized T cells (Meeusen, 1999).

\section{Moniezia spp.}

During the present study, no considerable changes were detected in Moniezia spp. infection. But it is well known that they cause indigestion, diarrhoea and are associated with the poor absorption of ready-made nutrients resulting malnutrition. 
The present study clearly suggests that Black Bengal goats are susceptible to intestinal helminths in both winter and summer seasons and most of the parasites recovered are associated with the production of variable degree of pathological lesions. That is why, proper attempts should be made to control all these parasites.

\section{REFERENCES}

1. Agrawal V (1966). The effects of temperature on the survival and development of the free-living stages of Oesophagostomum columbianum (Curtice, 1890) (Nematodes), Transactions of the American Microscopical Society 85: 99-106.

2. Asanji MF and Williams MO (1987). A qualitative and quantitative survey and seasonal dynamics of gastrointestinal helminth parasites of livestock in Sierra Leone, Bulletin of Animal Health and Production in Africa 35: $191-199$.

3. BBS (1986). Statistical Pocketbook of Bangladesh, Bangladesh Bureau of Statistics. (Statistics Division), Ministry of Planning, Government of the People Republic of Bangladesh, Dhaka, pp. 258.

4. $\quad$ Cable RM (1957). An Illustrated Laboratory Manual of Parasitology, $4^{\text {th }}$ edn., Burges Publishing Co., Minneapolis 15 , Minnesota, USA.

5. Devendra C (1970). Goat Production in the Tropics, Commonwealth Agricultural Bureaux, Farnham Royal, Bucks, England. p. 88.

6. FAO (2003). FAO Production Yearbook, Food and Agricultural Organization of the United Nations, Rome, Italy. Vol. 57, p. 147.

7. Haq S and Shaikh H (1968). A Survey of Helminth Parasiting the Gastro-intestinal Tracts of Goats and Sheep in East Pakistan. East Pakistan Journal of Veterinary Science 2: 54-62.

8. Hassan Z (1964). Investigation into the intestinal helminths load in local goats. Indian Veterinary Journal 41: 543-546.

9. Kotpal RL (2001). Modern Textbook of Zoology, Invertebrates, $8^{\text {th }}$ edn.; Rastogi Publication, New Delhi, India, p. 158.

10. Kumar S and Lal SS (1987). Oedema due to Trichuris ovis: a case report. Archiva Veterinaria 18: 33-36.

11. Lapage G (1962). Mönnig's Veterinary Helmithology and Entomology. $5^{\text {th }}$ edn., Bailliere, Tindall and Cox Ltd. London, pp. 213-214.

12. Luna LG (1968). Manual of Histologic Staining Method of the Armed Forces Institute of Pathology. $3^{\text {rd }}$ edn., McGrawHill Book Company, New York.

13. Meeusen NT (1999). Immunology of helminth infections, with special reference to immunopathology. Veterinary Parasitology 84: 259-273.

14. Mondal MMH and Islam MK (1994). Prevalence and pathological effects of Trichuris infection in Black Bengal goats. Bangladesh Veterinary Journal 28: 15-20.

15. Mostafa MG (1989). Methods of Statistics. Fourth edn., Karim Press and Publications, Dhaka, pp. $296-298$.

16. Patel MD, Nauriyal DS, Hasnani JJ and Gupta RS (2001). Prevalence of gastrointestinal parasitism in goats maintained under semi-intensive and field management systems. Indian Journal of Veterinary Medicine 21: 99-101.

17. Petrie A and Watson P (1999). Statistics for Veterinary and Animal Science. First edn., Blackwell Science, USA, pp. 81-85.

18. Powers KG (1961). Bionomics of the genus Trichuris Roederer, in sheep. Dissertation Abstracts 22: $2116-2117$.

19. Qadir ANMA (1967). Investigation on the incidence of gastrointestinal parasites of goats in the East Pakistan Agricultural University Campus. Bangladesh Veterinary Journal 15: 58-61.

20. Qadir ANMA (1979). Natural infection of goats by male Schistosome. Bangladesh Veterinary Journal 13: 53-54.

21. Saha SB and Bhowmik MK (1998). Pathomorphological changes in spontaneous trichuriasis in goat. Indian Journal of Animal Health 37: 37-38.

22. Schesselman JJ (1982). Case Control Studies. $2^{\text {nd }}$ edn., Oxford University Press, New York, pp174-177.

23. Singh KP and Parihar NS (1990). Pathology of fluke infestations in livers of sheep and goats. Indian Journal of Animal Sciences 58: 890-894.

24. Smith HA, Jones TC and Hunt RD (1992). Veterinary Pathology. $4^{\text {th }}$ edn., Lea and Febiger, London, UK pp. $743-744$.

25. Soulsby EJL (1965). Textbook of Veterinary Clinical Parasitology. Vol. I- Helminths. Blackwell Scientific Publications Ltd., Oxford, UK pp.1120.

26. Soulsby EJL (1982). Helminth, Arthropod and Protozoa of Domesticated Animals. $7^{\text {th }}$ edn., Bailliere Tindall, London 809p.

27. Thangathurai R and Rao DGK (2002). Occurrence of enteric parasitism of goats in Bidar Region (Karnataka). Indian Journal of Animal Health 41: 151-152.

28. Urquhart GM, Armour J, Duncan JL, Dunn AM and Jennings FW (1996). Veterinary Parasitology. $2^{\text {nd }}$ edn., Blackwell Science Ltd., London pp. 102-103.

29. Yamaguti S (1961). Systema Helminthum, Vol. II. Interscience Publishers, Inc. New York. 